Article

\title{
Performance Expectations of Professional Sport Teams and In-Season Head Coach Dismissals-Evidence from the English and French Men's Football First Divisions
}

\author{
Yvon Rocaboy ${ }^{1, *(1)}$ and Marek Pavlik ${ }^{2}$ (i) \\ 1 Univ Rennes, CNRS, CREM-UMR 6211, Condorcet Center for Political Economy, F-35000 Rennes, France \\ 2 Faculty of Economics and Administration, Masaryk University, 60177 Brno, Czech Republic; \\ marek.pavlik@econ.muni.cz \\ * Correspondence: yvon.rocaboy@univ-rennes1.fr
}

Received: 25 August 2020; Accepted: 11 September 2020; Published: 9 October 2020

check for updates

\begin{abstract}
The goals of this paper are first to identify why professional football clubs replace their head coach and, second, to investigate the effect of coach dismissal on team performance. To do that, we propose a new method for assessing the performance expectations of professional sport teams using Monte Carlo simulation. We apply our method to the English Premier league and the French Ligue 1 football teams over the 2015-2016 and 2016-2017 seasons. We find that coach dismissal is the result of a drop in the average expected performance compared with the performance expectations at the beginning of the season. We also show that dismissing a coach may enhance performance only if the team under-performed before the dismissal. There is no obstacle to using the same method for professional teams in other sports. The method is easily reproducible and does not require much information in order to be applied.
\end{abstract}

Keywords: coach dismissal; Monte Carlo simulation; team performance; payrolls; expectations

\section{Introduction}

Football is one of the most popular sports in the world, and the impact of "the beautiful game" on the international economy is growing fast (Ashtonet et al. 2011). As a consequence, it has become a major subject of interest for researchers (Salgado-Barandela et al. 2017). Nowadays, football means big money, and the economic consequences of failure can be huge for professional football teams playing in the national first divisions. Deloitte Business Group estimates that relegation for any English Premier League team costs approximately $£ 50$ million. Not surprisingly, a lacklustre performance is a cause for concern for owners of professional football teams and attracts a lot of media interest (van Ours and van Tuijl 2016). One of the most frequent decisions made by football team owners in such a situation is to dismiss their head coach. Based on 22 years of data, Frick et al. (2010) state that on average $36 \%$ of head coaches are dismissed during a season in the German Bundesliga. As regards the French Ligue 1 and the English Premier League during the 2015-2016 and 2016-2017 seasons, 31 head coaches were dismissed or left their clubs before the end of the season. The prevalence of dismissal cases is quite high everywhere, even though it may differ from one league to another. For example, Flores et al. (2012) report that the head coaches in Argentina are dismissed more often than in Europe.

Head coaches are key actors in professional sports because of the strong impact they are expected to have on the performance of their team (Detotto et al. 2018). It is true that, quite often, their role is not just coaching. Most of them also have the power to recruit the football players of their choice and to pick the team for games from the squad. This is the case in the French and UK professional football leagues, where the role and power of head coaches are very similar. Even if the quality of 
the individual players under contract seems to be the main determinant of the final league position of a team, Frick et al. (2010) suggest that the influence of the head coach on team performance is far from negligible.

Most papers examine two questions connected with head coach replacement. First, why and when is the head coach dismissed? Second, what is the effect of dismissal on team performance? These questions have been raised for the main American and European professional team sports: football, American football, baseball, basketball, and ice hockey (Koning 2003; Holmes 2011; Hill 2009; White et al. 2007).

The literature provides various reasons that head coaches are dismissed (Allen and Chadwick 2012). One obvious reason is poor team performance attributed to bad coaching. If results do not match the club's expectations, owners start to make changes, including coach dismissal, in order to achieve the expected results. The correlation between coach replacement and poor game results has been well documented in recent years, (for example, in Barros et al. 2009; Hughes et al. 2010; Frick et al. 2010; van Ours and van Tuijl 2016). Being in the relegation zone may trigger a coach dismissal (de Dios Tena and Forrest 2007). Some authors have compared expectations (expressed as bookmaker odds) with actual results and suggest that a string of outcomes below expectations may lead to coach dismissal (van Ours and van Tuijl 2016; Pieper et al. 2014). Even if poor past performance seems to be the main determinant of the decision to dismiss, some other variables may also play a role in that decision, including the race, sex, ethnicity, and salary of the head coach (Mixon and Trevino 2004; Kahn 2006).

There is no clear-cut answer regarding the effects of coach turnover on team performance. A recent comprehensive review of the literature is found in Scelles and Llorca (2020). They identify 32 studies addressing that issue regarding 12 different countries. Among these studies, 11 find no significant improvement in performance after a coach replacement, 11 a negative impact, and 10 studies find a positive effect. The empirical results may depend on the period of time under scrutiny, that is, short-term versus long-term periods (Lago-Peñas 2011; Hughes et al. 2010; Audas et al. 2006), and also on the methods used.

The key point of those studies is how to measure team performance. Most of the time, performance is measured on short-term results, for example over the 3,4, or 5 games prior to dismissal, and it is expressed as the number of points won, the number of goals scored and allowed, the change in the league position, or the presence in the relegation zone (Salomo and Teichmann 2000; Frick et al. 2010; d'Addona and Kind 2014; Pieper et al. 2014). In this paper, we propose an innovative evaluation method of professional sports team performance based on Monte Carlo simulations. This technique makes it possible to estimate the probability distribution of the final team ranking and thus to calculate the expected final league position of teams. The computation of those probability distributions is based on team payroll. That expected final ranking is revised after each game day. Expected performance (over- or under-performance) at game day $t$ is measured by the difference between the expected final ranking calculated at the beginning of the season and the expected final ranking knowing the results of the first $t$ game days ${ }^{1}$.

We use that method to assess the performance of the English Premier League and the French Ligue 1 professional football teams over the 2015-2016 and 2016-2017 seasons. We show that the failure to perform according to expectations over the season is the main reason for the decision to dismiss head coaches: $93 \%$ of teams with an average expected final ranking two positions lower than what was expected at the beginning of the season dismissed their coach. That percentage falls to $83 \%$ for teams whose average expected final ranking is lower than the expected final ranking before the season started by one position. We also find that coach replacement improves performance only when

1 Scelles and Llorca (2020) also chose expected performance as a measure of performance but they use the expected number of points as calculated by betting companies, and not the expected ranking. 
the teams under-performed before the dismissal. If the teams performed well before the coach was dismissed, the dismissal hinders performance.

The rest of the paper is as follows. Section 2 gives the team probabilities of winning, drawing, or losing a game computed from the team payroll. Section 3 presents the performance evaluation method based on a Monte Carlo simulation. In Section 4, we use that method to establish a link between performance and coach dismissal. In Section 5, we investigate the relation between dismissal and performance. Finally, we present our conclusions in Section 6 and comment on our results.

\section{The Probability of Winning, Drawing, or Losing a Game}

Calculating the probability of winning, drawing, or losing a game is the first step in building our stochastic model. We define those probabilities as contest success functions depending on the relative total payroll of the teams. We assume that the probability of team $i$ winning against team $j$ is not the same whether team $i$ plays at home or away. The probability that team $i$ wins, loses, or draws at home against team $j$ on game day $t$ is given as:

$$
w_{t}^{H i j}=\frac{m^{i}}{m^{i}+m^{j}}, l_{t}^{H i j}=\lambda \frac{m^{j}}{m^{i}+m^{j}} \quad \text { and } \quad d_{t}^{H i j}=(1-\lambda) \frac{m^{j}}{m^{i}+m^{j}},
$$

where $m^{k}$ is the total payroll of team $k(k=i, j)$. This variable is supposed to be a proxy for team $k$ 's stock of talent (Breunig et al. 2014). From the previous set of probabilities, we can deduce the probabilities that team $j$ wins, loses, or draws in an away game against team $i$. We have:

$$
w_{t}^{A j i}=l_{t}^{H i j}=\lambda \frac{m^{j}}{m^{i}+m^{j}}, l_{t}^{A j i}=w_{t}^{H i j}=\frac{m^{i}}{m^{i}+m^{j}} \quad \text { and } \quad d_{t}^{A j i}=d_{t}^{H i j}=(1-\lambda) \frac{m^{j}}{m^{i}+m^{j}} .
$$

Parameter $\lambda$ has two functions. First, it allows us to compute the probability of team $i$ losing or drawing at home. If $\lambda=0$, the home team never loses (wins or draws) and if $\lambda=1$, the home team never draws (wins or loses). Second, it may also be considered as a measure of the Home/Away effect. The difference between the probability of team $i$ winning against team $j$ at home and in an away game is given by:

$$
\Delta w_{t}^{i j}=w_{t}^{H i j}-w_{t}^{A i j}=(1-\lambda) \frac{m^{i}}{m^{i}+m^{j}} .
$$

Similarly we get:

$$
\Delta d_{t}^{i j}=d_{t}^{H i j}-d_{t}^{A i j}=(1-\lambda) \frac{m^{j}-m^{i}}{m^{i}+m^{j}}
$$

and

$$
\Delta l_{t}^{i j}=l_{t}^{H i j}-l_{t}^{A i j}=-(1-\lambda) \frac{m^{j}}{m^{i}+m^{j}} .
$$

The lower $\lambda$, the higher the Home effect. As we may see, for $\lambda \in[0,1], \Delta w_{t}^{i j}>0, \Delta l_{t}^{i j}<0$, while the sign of $\Delta d_{t}^{i j}$ is ambiguous. Thus, a team has a higher chance of winning and a lower chance of losing when it plays a home game. In the same way, we can compute $w_{t}^{H j i}, l_{t}^{H j i}$ and $d_{t}^{H j i}$ and deduce $w_{t}^{A i j}, l_{t}^{A i j}$ and $d_{t}^{A i j}$. Table 1 displays those probabilities.

Table 1. Probabilities of winning, drawing, or losing for home and away teams.

\begin{tabular}{ccccc}
\hline & & \multicolumn{2}{c}{ Away Team $j$} \\
\hline & Prob. of Winning & Prob. of Drawing & Prob. of Losing \\
\hline Home Team $i$ & $\begin{array}{c}\text { Prob. of Winning } \\
\text { Prob. of Drawing } \\
\text { Prob. of Losing }\end{array}$ & $\frac{\lambda m^{j}}{m^{i}+m^{j}}$ & $\frac{(1-\lambda) m^{j}}{m^{i}+m^{j}}$ & $\frac{m^{i}}{m^{i}+m^{j}}$ \\
\hline
\end{tabular}


We consider a league championship to be a competition among professional sport teams organized by a league, each team playing against each other twice a season (at home and away). For football, that competition is known as the English Premier League in England and the Ligue 1 in France. From this set of probabilities, we can compute the expected total number of points each team may win when the league championship is composed of $n$ teams. The expected number of points for team $i$ against team $j$ at home, $E P^{H i j}$, is written as:

$$
E P^{H i j}=\frac{m^{i}}{m^{i}+m^{j}} p^{w}+(1-\lambda) \frac{m^{j}}{m^{i}+m^{j}} p^{d}
$$

where $p^{w}$ and $p^{d}$ are the points assigned for a win and a draw respectively, no point is assigned for a loss. Similarly, the expected number of points for team $i$ against team $j$ in an away game, $E P^{A i j}$, is as follows:

$$
E P^{A i j}=\lambda \frac{m^{i}}{m^{i}+m^{j}} p^{w}+(1-\lambda) \frac{m^{i}}{m^{i}+m^{j}} p^{d} .
$$

It yields the expected number of points won by team $i$ against team $j$ :

$$
E P^{i j}=(1+\lambda) \frac{m^{i}}{m^{i}+m^{j}} p^{w}+(1-\lambda) p^{d}
$$

and team $i$ 's expected total number of points:

$$
E P^{i}=\sum_{j \neq i} E P^{i j}=(1+\lambda) \sum_{j \neq i} \frac{m^{i}}{m^{i}+m^{j}} p^{w}+(n-1)(1-\lambda) p^{d}
$$

Finally, after a few computation steps, we end up with the expression for the league championship expected total number of points as:

$$
E P=\sum_{i} E P^{i}=(1+\lambda) \frac{n(n-1)}{2} p^{w}+n(n-1)(1-\lambda) p^{d},
$$

where $n$ is the number of teams playing in the league championship (20 teams in the Ligue 1 and English Premier League). To run our simulations (shown in the next section), we need to estimate the value of $\lambda$. From Equation (10), that value may be expressed as:

$$
\lambda=\frac{2}{p^{w}-2 p^{d}}\left(\frac{E P}{n(n-1)}-\frac{p^{w}+2 p^{d}}{2}\right) .
$$

To estimate $\lambda$, we replace $E P$ with the total number of points won over the season. For the English Premier League, that number is equal to 1033 for the 2015-2016 season and 1056 for the 2016-2017 season, and to 1032 and 1046 for the Ligue 1. Replacing EP with those numbers in Equation (11) and knowing that $n=20, p^{w}=3$ and $p^{d}=1$ gives us for $\lambda$ : 0.43 and 0.55 for the English Premier League and 0.42 and 0.5 for the Ligue 1 . In the simulations, we take the average value of $\lambda$, that is, $\lambda=0.47$.

\section{The Expected Performance of the English Premier League and Ligue 1 Football Teams from Monte Carlo Simulation}

We take the English Premier League and the Ligue 1 fixtures for the 2015-2016 and 2016-2017 seasons, and we use a Monte Carlo simulation method to produce probability distributions for the final league positions of the teams. Using the total wage costs as a measure for the team payrolls (see Table 2), we run a simulation model to generate 10,000 point paths for each team. A path displays at each game day the number of points a team has accumulated over the previous 
game days. The point paths are the results of a stochastic process in that the number of points the teams win at each game day is random and depends on the probability of winning, drawing, or losing the game. To compute that number, we use the RandomChoice command of Mathematica, which gives us the pseudorandom choice of getting 3,1 , or 0 points weighted by the probability of winning, drawing, or losing the game, as specified in Section $2^{2}$. More precisely, the number of points home team $i$ wins against away team $j$ at game day $t$ is given by the following Mathematica command: RandomChoice $\left[\left\{w_{t}^{H i j}, d_{t}^{H i j}, l_{t}^{H i j}\right\}->\{3,1,0\}\right]$. By running the simulations, we act as if the 2015-2016 and 2016-2017 seasons were played 10,000 times. Thus, we get 10,000 rankings of teams and we can compute the number of times a team was ranked 1st, 2nd, .., 20th, which gives us the probability distribution of final position for each team and allows us to compute the expected final ranking of teams. Being based on exogenous factors, the teams' wage costs, those rank expectations cannot be manipulated by any stakeholder (owners or shareholders, sponsors, head-coaches, players, media, bookmakers, ....).

Table 2. Clubs' Wage costs for season 2015-2016 and 2016-2017 (€m).

\begin{tabular}{|c|c|c|c|c|c|}
\hline \multicolumn{3}{|c|}{ English Premier League } & \multicolumn{3}{|c|}{ Ligue 1} \\
\hline & 2015-2016 & 2016-2017 & & 2015-2016 & 2016-2017 \\
\hline Chelsea & 217 & 218 & Paris Saint Germain & 254.8 & 292.4 \\
\hline Manchester United & 203.8 & 220.8 & Olympique de Marseille & 96.8 & 92.6 \\
\hline Manchester City & 193.8 & 225 & AS Monaco & 84.2 & 82.5 \\
\hline Arsenal & 192.2 & 200.5 & Olympique Lyonnais & 75 & 100 \\
\hline Liverpool & 166.6 & 165.6 & Girondins de Bordeaux & 50.9 & 50.5 \\
\hline Tottenham & 107.3 & 121.2 & Lille OSC & 48.2 & 49.5 \\
\hline Aston Villa & 87 & & AS Saint-Etienne & 41.7 & 48.3 \\
\hline Swansea City & 82.5 & 59 & Stade Rennais FC & 40.2 & 44 \\
\hline Southampton & 80.4 & 63.6 & Montpellier Hérault SC & 33.5 & 31.6 \\
\hline Everton & 77.5 & 83 & Toulouse FC & 25.6 & 25.5 \\
\hline Sunderland & 77.1 & 68.3 & OGC Nice & 24.9 & 31.7 \\
\hline West Ham United & 72.7 & 79.8 & EA Guingamp & 21.8 & 21.7 \\
\hline $\begin{array}{l}\text { West Bromwich } \\
\text { Albion }\end{array}$ & 69.8 & 65 & SC Bastia & 21.5 & 20.9 \\
\hline Crystal Palace & 68 & 55 & FC Lorient & 21.4 & 21.5 \\
\hline Stoke City & 66.6 & 75.9 & Stade de Reims & 20.7 & \\
\hline Newcastle United & 65 & & SM Caen & 19.5 & 27.2 \\
\hline Leicester City & 57.4 & 66 & FC Nantes & 17.3 & 22.2 \\
\hline Norwich City & 37 & & ESTAC Troyes & 11.8 & \\
\hline Watford & 29 & 41 & Angers SCO & 8.8 & 15.8 \\
\hline Bournemouth & 25 & 34 & Gazélec FC Ajaccio & 3.5 & \\
\hline Middlesbrough & & 34 & FC Metz & & 14.5 \\
\hline Burnley & & 33 & AS Nancy-Lorraine & & 10 \\
\hline Hull City & & 25 & Dijon FCO & & 8.9 \\
\hline
\end{tabular}

Sources: Comptes individuels des clubs, DNCG, 2014-2015 and 2015-2016 and Annual Review of Football Finance 2016.

The Figures 1-3 depict the 10,000 point paths (on the left-hand side of the figures) and the probability distribution of final positions (on the right-hand side of the figures) for a few Ligue 1 and English Premier League teams over the 2015-2016 season, namely Toulouse Football Club, Leicester City, and Manchester City. Two examples are depicted in the figures: the point paths computed at the beginning of the season (first line of the figures) and the point paths computed at mid-season, that is, at game day 19, after knowing the results of the first 19 games (second line of the figures). On the point path figures, the dashed curve is the expected point path. It displays the

2 A pseudorandom number generator typically exhibits statistical randomness while being an entirely deterministic causal process. It is widely used in simulation exercises, for example for the Monte Carlo method. 
average accumulated number of points resulting from the simulations, and the solid curve gives the real accumulated number of points obtained by the team over the season. If the solid curve is below the dashed curve at date $t$, the team has under-performed over the first $t$ game days. For example, Toulouse has consistently performed below what was expected at the beginning of the season and the solid curve is below the dashed curve over the 38 game days; it is the opposite for Leicester City. The performance of Manchester City is very close to what was expected when the season started.
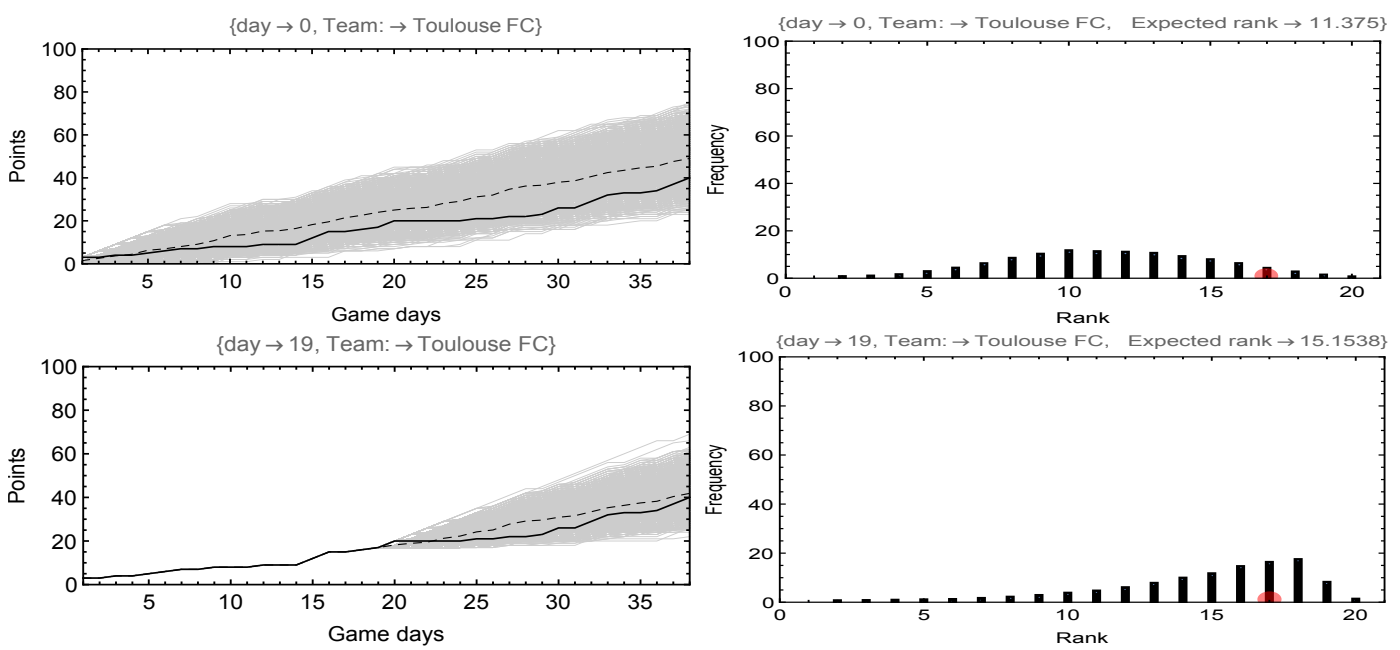

Figure 1. Point paths and frequency of Ranks for French Ligue 1 Toulouse Football club over season 2015-2016.
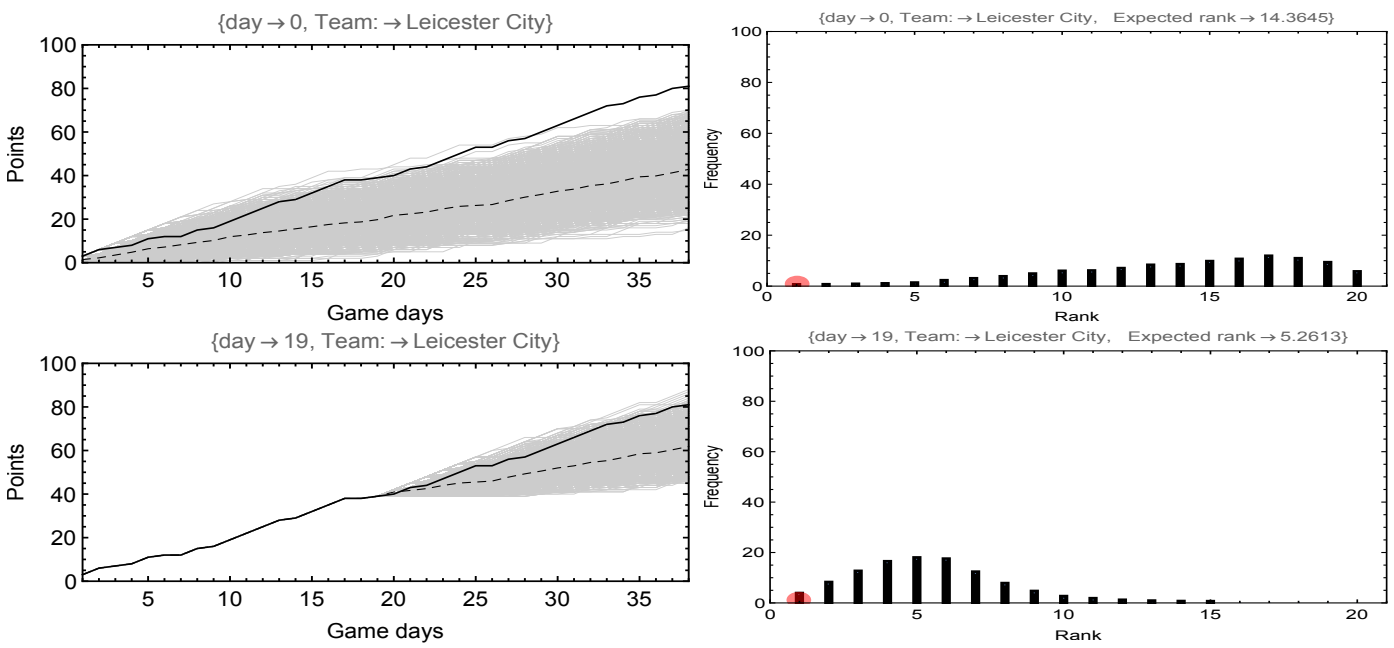

Figure 2. Point paths and frequency of Ranks for English Premier League Leicester over season 2015-2016. 

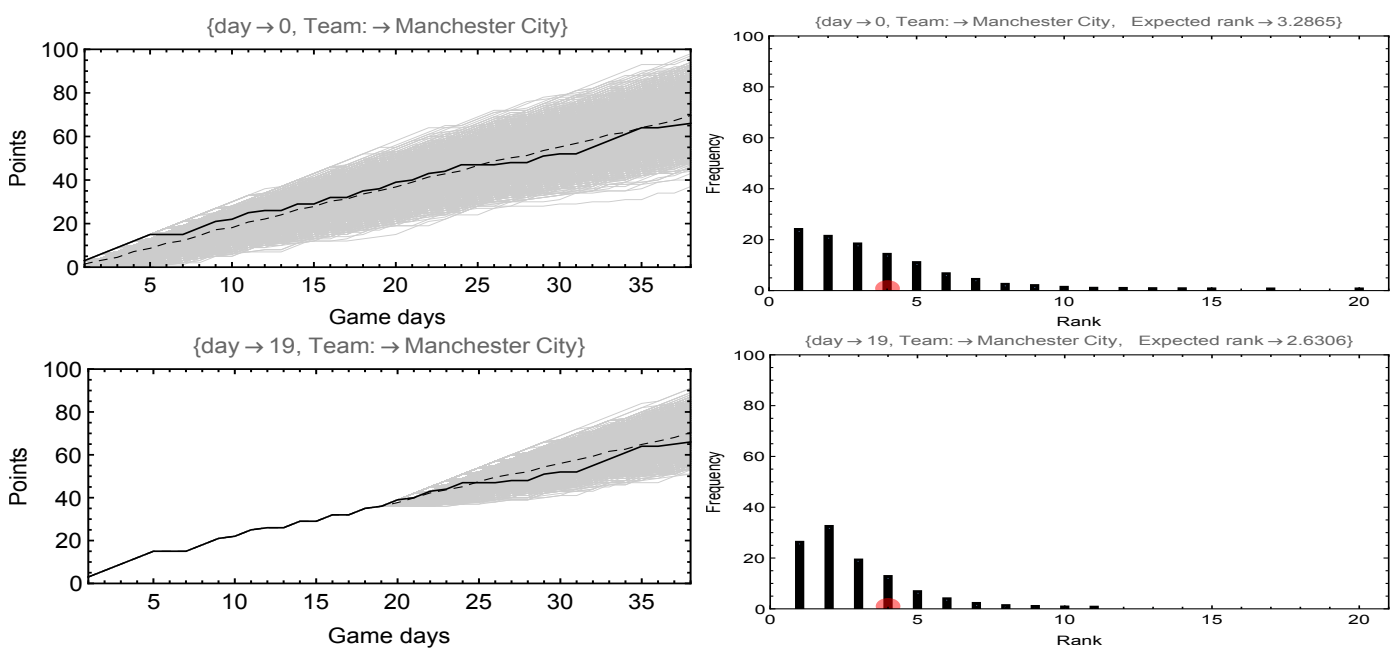

Figure 3. Point paths and frequency of Ranks for English Premier League Manchester city over season 2015-2016.

On the figures showing the probability distribution of ranks (right-hand side of the figures), the bars give the team probability of ending 1 st, 2 nd, .., 20th. The expected final rank is the product of the probability and the rank. For example, the expected final rank computed at the beginning of the season is 11.375 for Toulouse (see Figure 1). On the same figures, the dot shows the observed final rank. Toulouse ended 17th. The expected final rank of a team may also be revised at any game day $t$ by taking into account the observed total number of points won over the first $t$ game days. For example, the expected final rank of Manchester City computed at game day 19 is equal to 2.63 (see Figure 3). This is the result of a non-random component, the total number of points Manchester City won over the first 19 game days, and from a random component, namely, the number of points the team could win after game day 19.

We measure the under- or over-performance of team $i$ at game day $t$ as the difference between the expected final rank computed at that date (knowing the results of the $t$ first game days) and the expected final rank computed at the beginning of the season (without any information regarding the results of the team over the first $t$ game days). We call that difference the expected margin, $E M_{i}^{t}$ :

$$
E M_{i}^{t}=E R_{i}^{t}-E R_{i}^{0},
$$

where $E R_{i}^{0}$ and $E R_{i}^{t}$ denote the expected final rank of team $i$ at dates 0 (before the season starts) and $t$ respectively. A positive expected margin at game day $t$ means that the team performance expectation at that date is worse than what was expected at the beginning of the season. Conversely, when the expected margin is negative, the performance of the team is better in expectation than what its relative payroll would have suggested at the beginning of the season.

Figures 4 and 5 display the evolution of the expected margin for the 20 teams of the French Ligue 1 and the English Premier League respectively, for the 2015-2016 season. The same is provided in Figures 6 and 7 for the 2016-2017 season. As an example, let us consider the evolution of the expected rank for Marseille over the 2015-2016 season (second figure of Figure 4). At the beginning of the season (Game day 0), the expected final rank for Marseille was 3.28. Until game day 26, Marseille performed slightly less well than what was expected at game day 0 . Its expected rank amounted to 5 on average. After game day 26, there was a dramatic increase in the expected final rank of the team. At game day 34, Marseille coach, Míchel, was dismissed. The expected margin at the date of dismissal was around 8.5. Marseille ended 13th. 

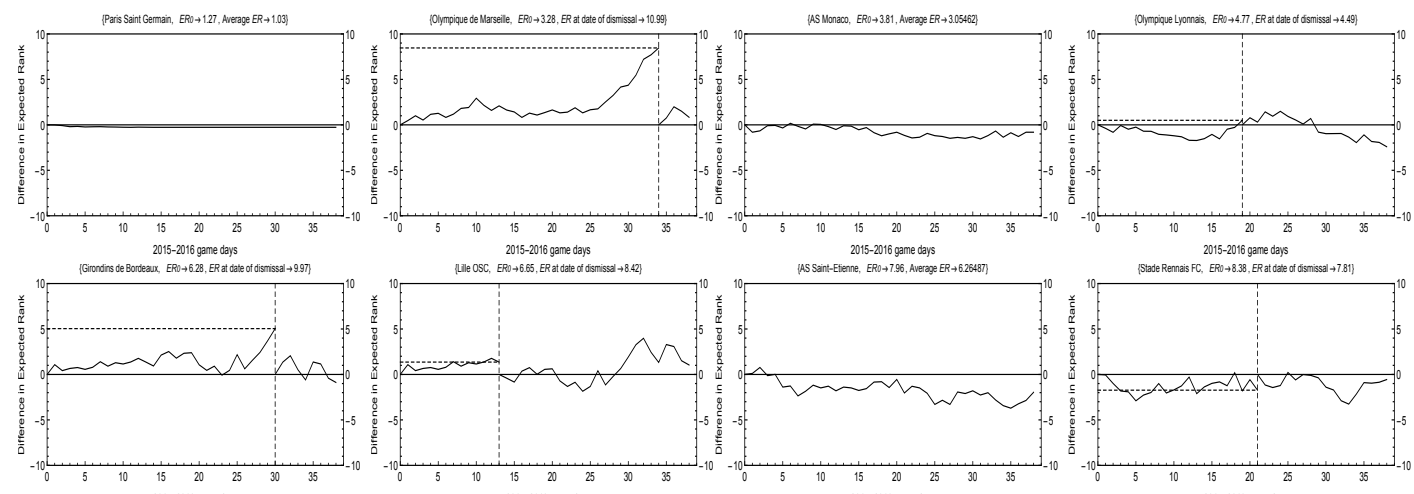

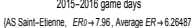
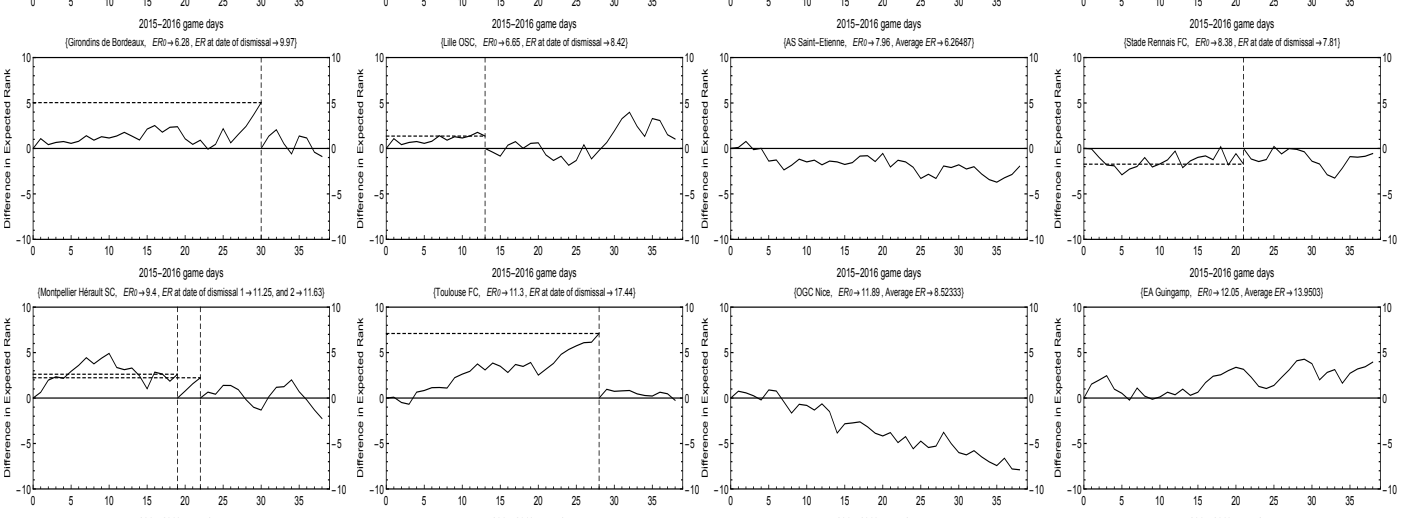

$2015-2016$ game dajs
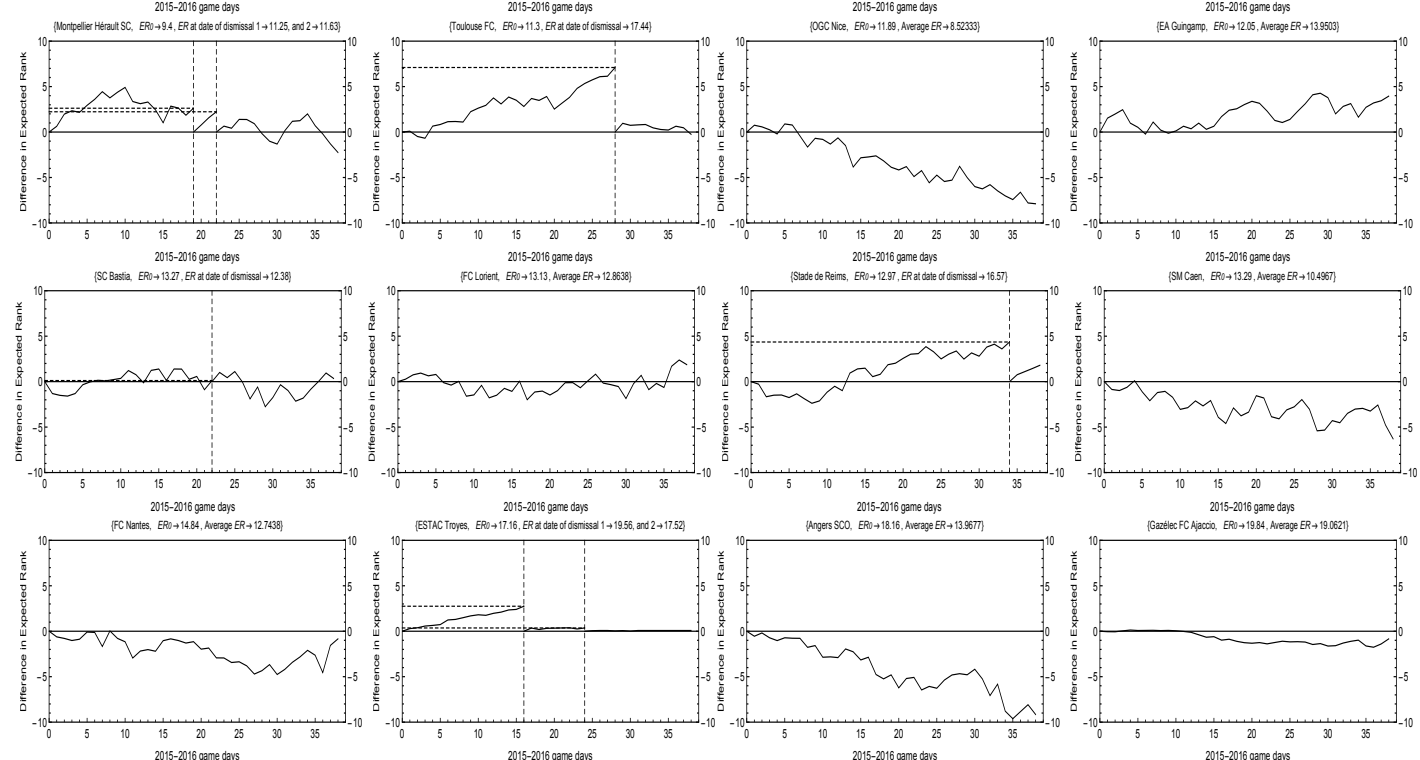

2015-2016 gamed days

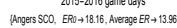

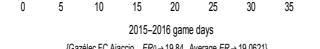

Figure 4. Expected margin: Difference between the expected rank at game day $t$ and the expected rank at game day $0\left(E M_{t}=E R_{t}-E R_{0}\right)$ for French Ligue 1 clubs (Season 2015-2016).
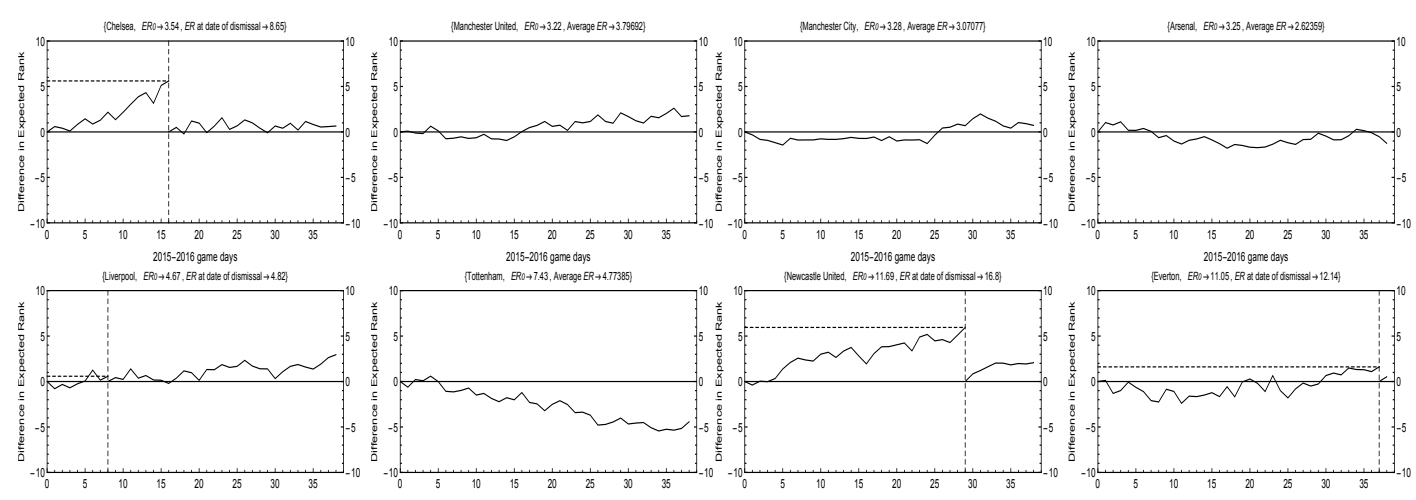

$2015-2016$ ganeredeys
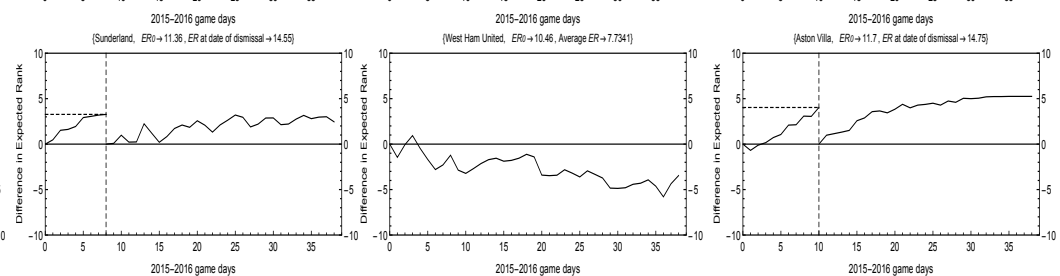

Figure 5. Cont. 

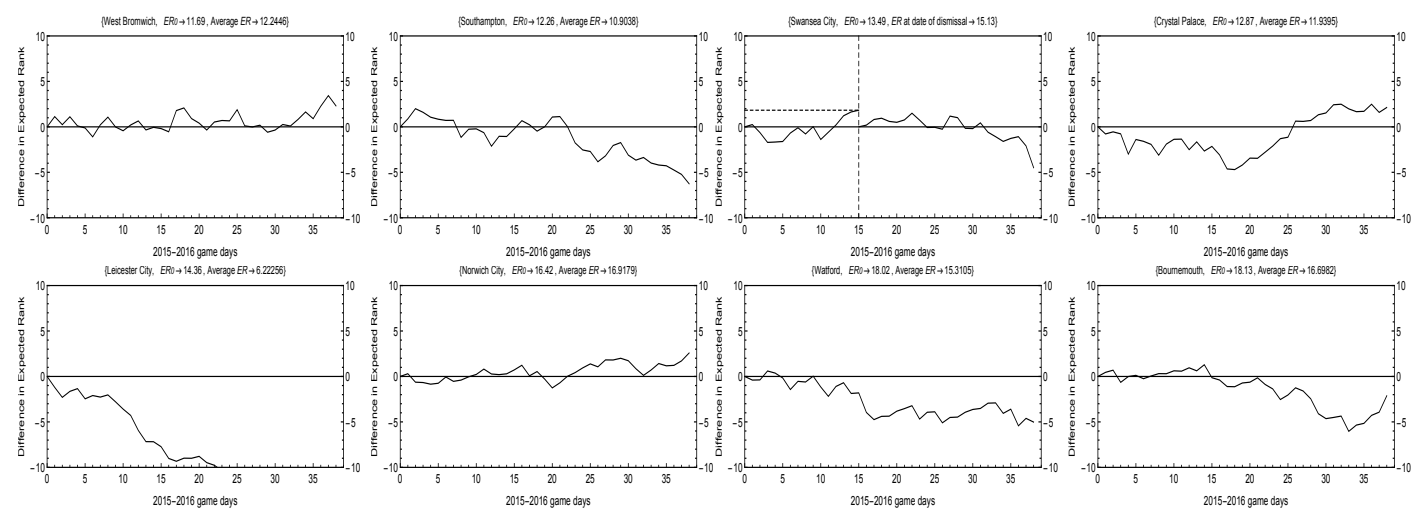

Figure 5. Expected margin: Difference between the expected rank at game day $t$ and the expected rank at game day $0\left(E M_{t}=E R_{t}-E R_{0}\right)$ for English Premier League clubs (Season 2015-2016).
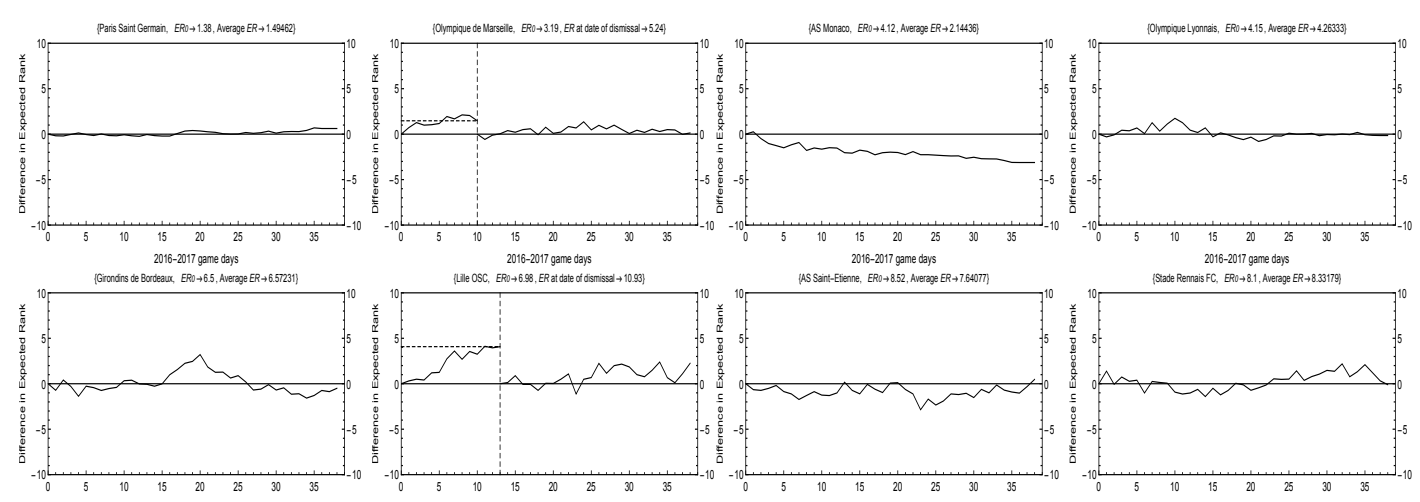

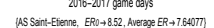

$2016-2017$ game dars
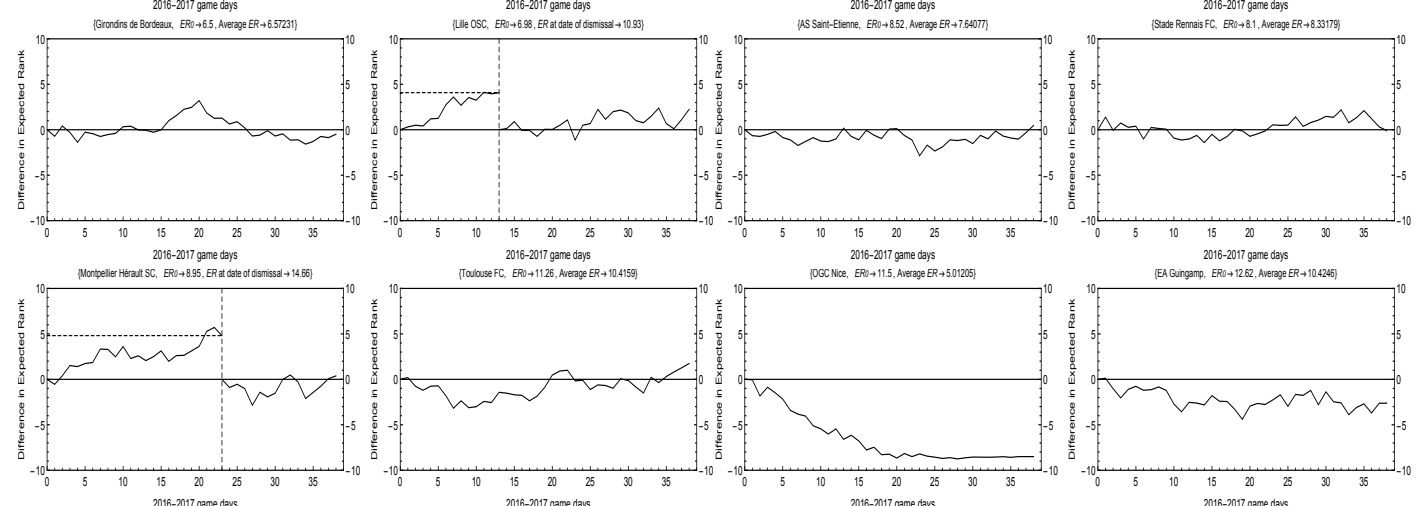

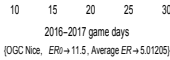

2016-2017 game days
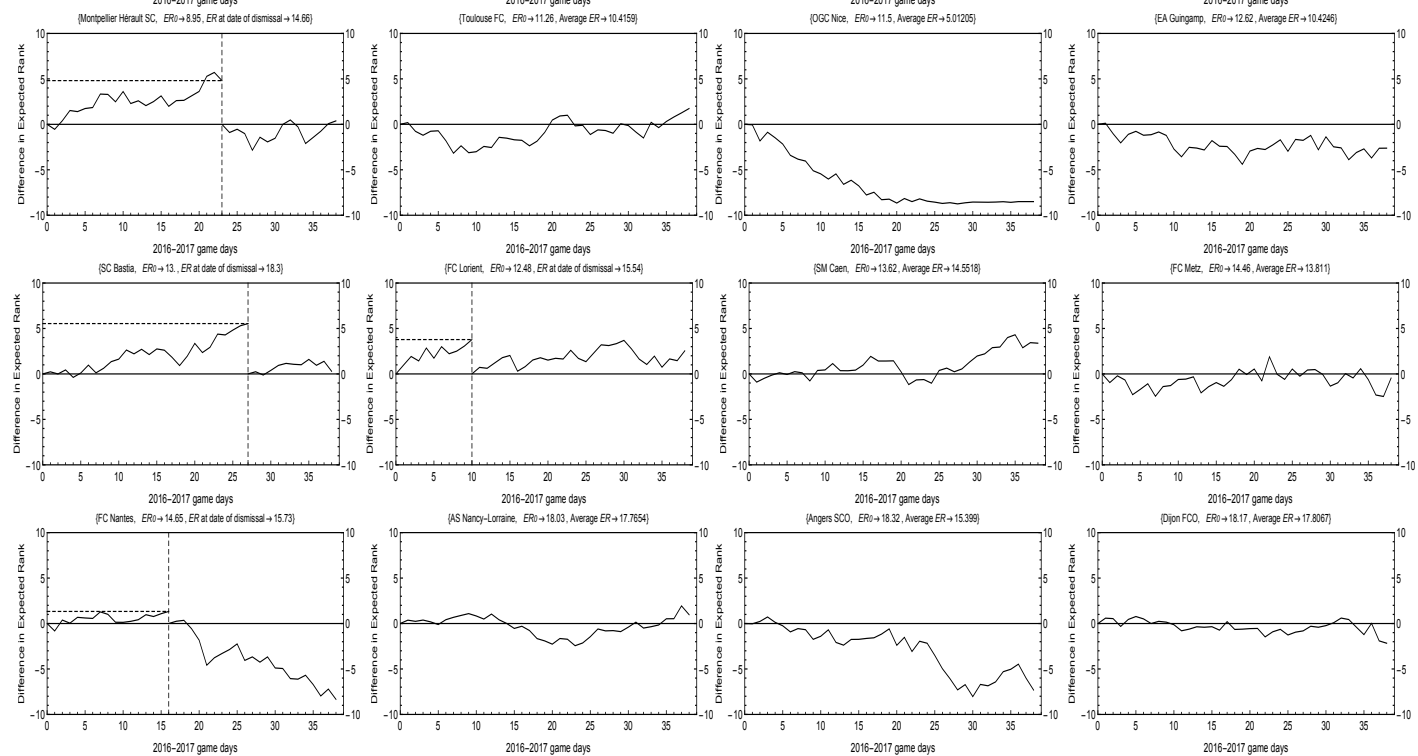

Figure 6. Expected margin: Difference between the expected rank at game day $t$ and the expected rank at game day $0\left(E M_{t}=E R_{t}-E R_{0}\right)$ for French Ligue 1 clubs (Season 2016-2017). 

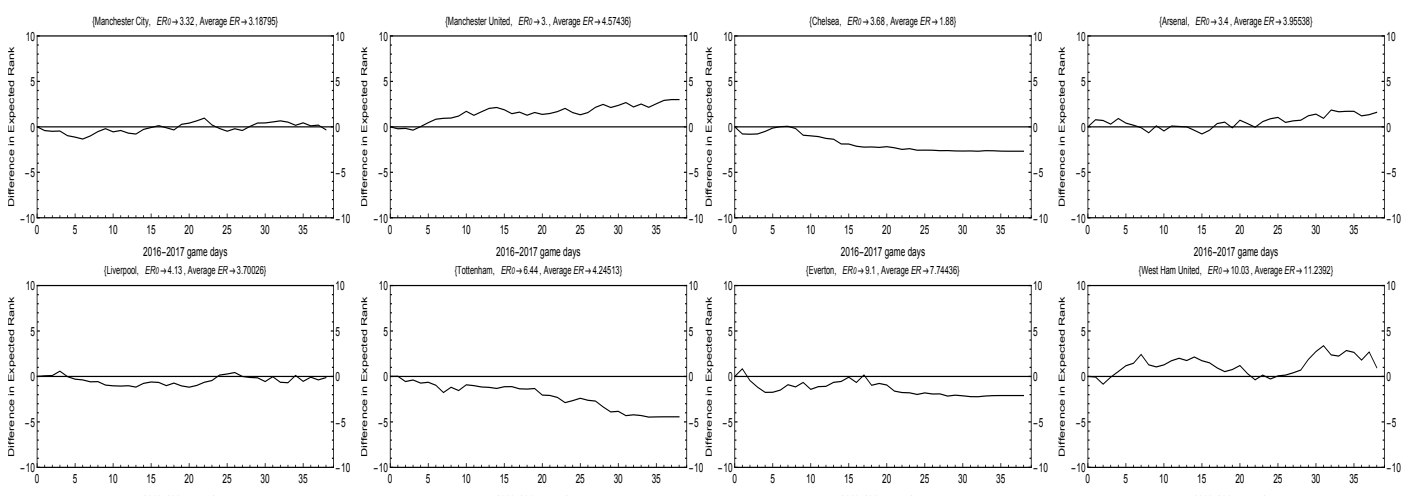

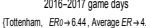

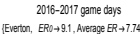

2016-2017 game days
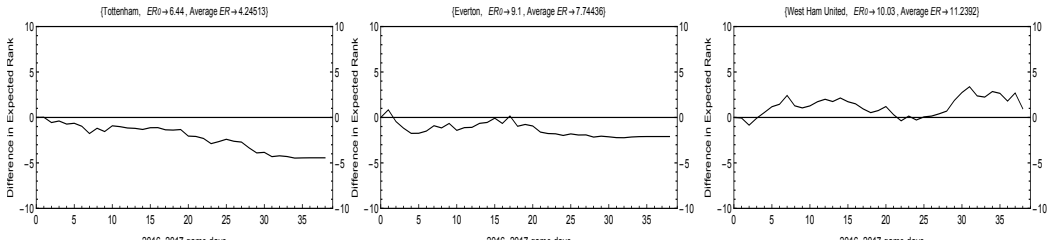

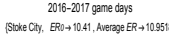
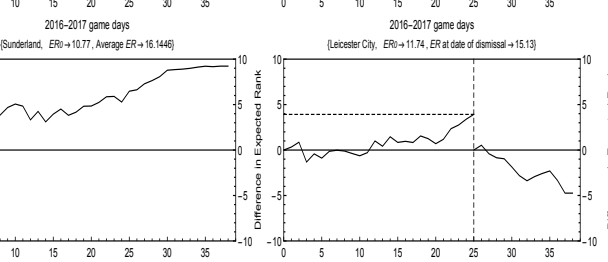

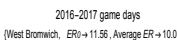
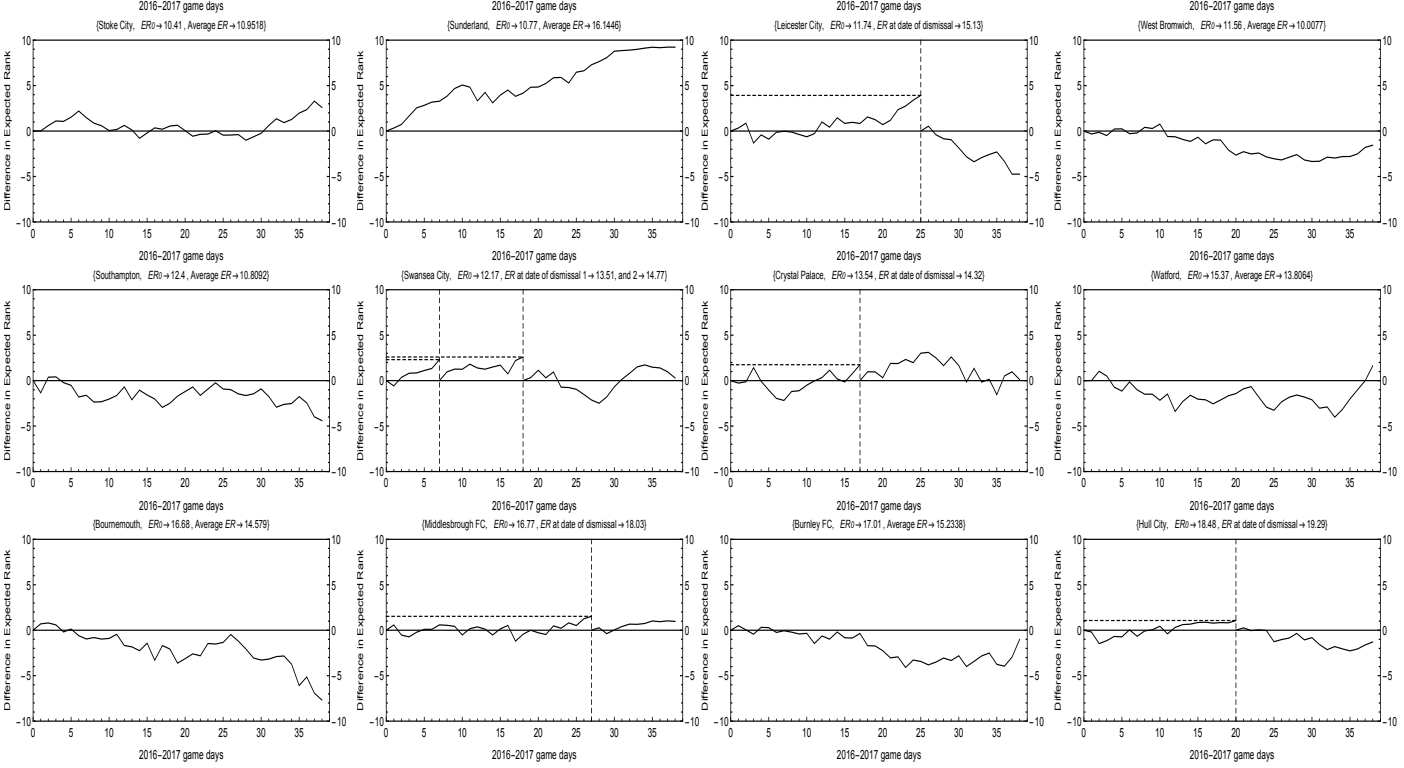

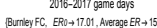
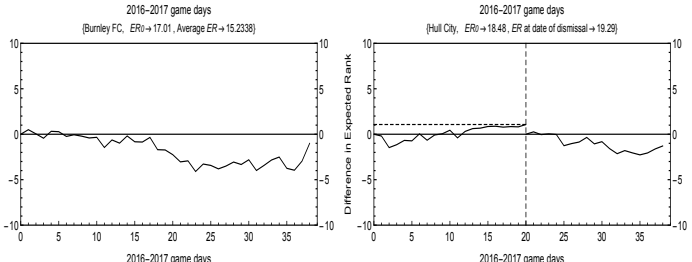

Figure 7. Expected margin: Difference between the expected rank at game day $t$ and the expected rank at game day $0\left(E M_{t}=E R_{t}-E R_{0}\right)$ for English Premier League clubs (Season 2016-2017).

For each game day, the sum of the teams' expected margins is equal to zero, because when one team performs better than expected, at least one other team under-performs. Formally, we have:

$$
\sum_{i=1}^{20} E M_{i}^{t}=0
$$

That result is easy to prove. For a league championship composed of 20 teams, we know that the expected final rank of team $i$ at game day $t, E R_{i}^{t}=p_{i}^{t, 1 \mathrm{st}} \times 1 \mathrm{st}+p_{i}^{t, 2 \mathrm{nd}} \times 2 \mathrm{nd}+\ldots+p_{i}^{t, 20 \text { th }} \times 20$ th, where $p_{i}^{t, r}$ is the probability computed at date $t$ that team $i$ will finish at rank $r$. Summing the expected ranks gives: $\sum_{i=1}^{20} E R_{i}^{t}=\sum_{i} p_{i}^{t, 1 s t} \times 1$ st $+\sum_{i} p_{i}^{t, 2 \text { nd }} \times 2$ nd $+\ldots+\sum_{i} p_{i}^{t, 20 \text { th }} \times 20$ th. Since $\sum_{i} p_{i}^{t, r}=1$, we get: $\sum_{i=1}^{20} E R_{i}^{t}=1+2+3+\ldots+20=210$. Finally, $\sum_{i=1}^{20} E M_{i}^{t}=\sum_{i=1}^{20}\left(E R_{i}^{t}-E R_{i}^{0}\right)=\sum_{i=1}^{20} E R_{i}^{t}-$ $\sum_{i=1}^{20} E R_{i}^{0}=210-210=0$.

According to this result, the sum of the expected margins of the under-performing teams at game day $t$ is equal to the opposite of that of the over-performing teams:

$$
\sum_{i=\{U P\}} E M_{i}^{t}=-\sum_{i=\{O P\}} E M_{i}^{t}
$$

where UP denotes the set of teams that under-performed $\left(E M_{i}^{t}>0\right)$ and $O P$ denotes the set of teams that over-performed $\left(E M_{i}^{t}<0\right)$. 
The average expected margin of team $i$ over the entire season, denoted $A E M_{i}$, is computed as:

$$
A E M_{i}=\frac{\sum_{t=1}^{38} E M_{i}^{t}}{38}
$$

where 38 is the number of game days. Of course, the previous results also hold for the average expected margin, namely:

$$
\sum_{i=1}^{20} A E M_{i}=0
$$

and

$$
\sum_{i=\{U P\}} A E M_{i}=-\sum_{i=\{O P\}} A E M_{i} .
$$

Note that $A E M_{U P}=\sum_{i=\{U P\}} A E M_{i}$ may be seen as a "Surprise Index" of the team rankings over the season. The higher $A E M_{U P}$, the less expected the final rankings of the teams on average over the season. The maximal value of $A E M_{U P}$ is 100 . This corresponds to a situation in which the team that was expected to finish 1st ended 20th $\left(A E M_{i}=20-1=19\right)$, and the one that was expected to finish 2nd ended 19th $\left(A E M_{i}=17\right)$, and so forth. In that case, $A E M_{U P}=\sum_{i=\{U P\}} A E M_{i}=$ $(19+17+15+\cdots+3+1)=100$. On the other hand, the minimal value of $A E M_{U P}$ is zero when the rankings on average are exactly those expected. We may express this "Surprise Index" in terms of the percentage of surprise: $S I=A E M_{U P} / 100$. The higher the $S I$, the more surprising or unexpected the season. If $S I=0 \%$, there was no surprise at all regarding the season; if $S I=100 \%$, the season was totally unexpected.

Table 3 reports the computation results of the average expected margins for the Ligue 1 and English Premier League teams over the 2015-2016 and 2016-2017 seasons. The teams are ranked with respect to their margin (in decreasing order). The upper part of the table shows the results for the under-performing teams $\left(A E M_{i}>0\right)$; the results of the over-performing teams are reported in the lower part of the table $\left(A E M_{i}<0\right)$. According to our "Surprise Index", the English Premier League 2015-2016 season was the most unexpected season ( $S I=21.73 \%$ ); the English Premier League 2016-2017 season was the least surprising one $(S I=14.78 \%)$. That index reaches $19.21 \%$ for the Ligue 1 2015-2016 season and 18.55\% for the Ligue 1 2016-2017 season. 
Table 3. Average expected margin (AEM) over seasons 2015-2016 and 2016-2017 for the Ligue 1 and English Premier League ${ }^{\text {a }}$.

\begin{tabular}{|c|c|c|c|c|c|c|c|}
\hline \multicolumn{4}{|c|}{ Season 2015-2016 } & \multicolumn{4}{|c|}{ Season 2016-2017 } \\
\hline \multicolumn{2}{|c|}{ Ligue 1} & \multicolumn{2}{|c|}{ English Premier League } & \multicolumn{2}{|c|}{ Ligue 1} & \multicolumn{2}{|c|}{ English Premier League } \\
\hline Club & $A E M_{i}$ & Club & $A E M_{i}$ & Club & $A E M_{i}$ & Club & $A E M_{i}$ \\
\hline Toulouse & 3.5875 & Aston Villa & 5.6405 & Lorient & 4.2181 & Sunderland & 5.4156 \\
\hline Montpellier & 3.5375 & Sunderland & 4.6018 & Lille & 3.9818 & Swansea City & 3.0851 \\
\hline Marseille & 2.9202 & Chelsea & 4.25 & Montpellier & 3.47 & Manchester United & 1.5783 \\
\hline Troyes & 2.2183 & Newcastle United & 3.8870 & Bastia & 3.2286 & West Ham United & 1.2483 \\
\hline Bordeaux & 1.9710 & Liverpool & 1.0713 & Marseille & 2.2010 & Crystal Palace & 1.0205 \\
\hline Guingamp & 1.8962 & Swansea City & 0.7472 & Caen & 0.8908 & Leicester City & 0.7940 \\
\hline Lille & 1.5697 & Manchester United & 0.56 & Rennes & 0.2470 & Middlesbrough FC & 0.6016 \\
\hline Reims & 1.5186 & West Bromwich & 0.5221 & Lyon & 0.1235 & Arsenal & 0.5421 \\
\hline$\ldots \ldots$ & $\ldots$ & Norwich City & 0.4551 & Paris SG & 0.1040 & Stoke City & 0.5010 \\
\hline \multirow[t]{2}{*}{$A E M_{U P}$} & 19.21 & & & Bordeaux & 0.0897 & & \\
\hline & & $A E M_{U P}$ & 21.73 & & & $A E M_{U P}$ & 14.78 \\
\hline Paris SG & -0.2456 & & & $A E M_{U P}$ & 18.55 & & $\ldots$ \\
\hline Lorient & -0.3310 & Stoke City & -0.1843 & & & Hull City & -0.1205 \\
\hline Bastia & -0.5802 & Manchester City & -0.44 & Nancy & -0.3051 & Manchester City & -0.1305 \\
\hline Monaco & -0.7743 & Everton & -0.4981 & Dijon & -0.3243 & Liverpool & -0.4494 \\
\hline Lyon & -0.7762 & Arsenal & -0.6264 & Metz & -0.6716 & Everton & -1.3721 \\
\hline Ajaccio & -0.7972 & Crystal Palace & -1.0383 & Toulouse & -0.9367 & Southampton & -1.5578 \\
\hline Rennes & -1.5129 & Southampton & -1.2602 & Saint-Etienne & -0.9397 & West Bromwich & -1.5940 \\
\hline Saint-Etienne & -1.7337 & Bournemouth & -1.4516 & Nantes & -1.6459 & Watford & -1.6921 \\
\hline Nantes & -2.1867 & Tottenham & -2.68 & Monaco & -1.9981 & Chelsea & -1.8248 \\
\hline Caen & -2.7743 & Watford & -2.7202 & Guingamp & -2.2432 & Burnley FC & -1.8448 \\
\hline Nice & -3.3354 & West Ham United & -2.7797 & Angers & -2.8810 & Bournemouth & -2.0070 \\
\hline Angers & -4.1713 & Leicester City & -8.0562 & Nice & -6.6089 & Tottenham & -2.1935 \\
\hline $\begin{array}{c}\ldots \ldots \\
A E M_{0 P}\end{array}$ & $\begin{array}{c}\ldots \\
-19.21\end{array}$ & $\begin{array}{l}\ldots \ldots \ldots \\
A E M_{0 P}\end{array}$ & $\begin{array}{c}\ldots \\
-21.73\end{array}$ & $\begin{array}{c}\ldots \ldots \\
A E M_{0 P}\end{array}$ & $\begin{array}{c}\ldots \\
-18.55\end{array}$ & ${ }_{A E M_{0 P}}$ & $\begin{array}{c}\ldots \\
-1478\end{array}$ \\
\hline $\begin{array}{l}1 L N 10 P \\
\ldots \ldots\end{array}$ & $\ldots$ & ........ & $\ldots$ & $\begin{array}{l}1 L N 10 P \\
\ldots \ldots\end{array}$ & $\ldots$ & ЖLW & $\ldots$ \\
\hline$\overline{A E M}_{D}$ & 1.4453 & $\overline{A E M}_{D}$ & 2.8142 & $\overline{A E M}_{D}$ & 2.5756 & $\overline{A E M}_{D}$ & 1.0761 \\
\hline$\overline{A E M}_{N d}$ & -1.4453 & $\overline{A E M}_{N d}$ & -1.5153 & $\overline{A E M}_{N d}$ & -1.1038 & $\overline{A E M}_{\mathrm{Nd}}$ & -0.3587 \\
\hline$\overline{A E M}_{D}$ & 1.9638 & & & & & & \\
\hline$\overline{A E M}_{N d}$ & -1.0574 & & & & & & \\
\hline
\end{tabular}

\section{The Dismissal of Head Coaches}

Over seasons 2015-2016 and 2016-2017, 31 coaches were dismissed or left their club before the end of the season, 18 in the French Ligue 1 and 13 in the English Premier League (see Table $4^{3}$ ). For the clubs which sacked their head coach, the game day just before dismissal is depicted by a vertical dashed line in the figures of Figures 4-7. As regards the Ligue 1, the average expected margin computed at the game day just before dismissal is equal to 3.32 and 3.50 for seasons 2015-2016 and 2016-2017 respectively and to 3.19 and 2.11 for the English Premier League. Regarding the two leagues and for the two seasons together, 28 clubs fired their coach and 52 did not.

We assume that the dismissals of head coaches are linked to the teams lack of performance. We hypothesis that dismissal is actually the consequence of under-performance ${ }^{4}$. Head coach dismissals thus should happen for teams displaying a positive average expected margin $\left(A E M_{i}>0\right)$. It is what our simulation results show on average: The mean average expected margin of teams which dismissed their coach, $\overline{A E M}_{D}$, is equal to 1.9638 , whereas that of teams which did not, $\overline{A E M}_{N d}$ is

3 We have not considered the coach replacements which took place before the season starts, for example, Claude Puel in Nice in May 2016, or right after the first game day, for example, Marcelo Bielsa in Marseille in August 2015.

4 It is worth noting that we do not know if under-performance is due to under-performing coaches or to over-performing ones, or both, or to any reason other than coach performance. 
equal to -1.0574 (see bottom of Table 3). Here also, there is a relationship between those two mean average expected margins. We know that:

$$
\sum_{i=\{N d\}} A E M_{i}=-\sum_{i=\{D\}} A E M_{i}
$$

where $D$ denotes the set of teams that dismissed their coach and $N d$ denotes the set of teams that did not dismiss their coach. We can write:

$$
n_{N d} \frac{\sum_{i=\{N d\}} A E M_{i}}{n_{N d}}=-n_{D} \frac{\sum_{i=\{D\}} A E M_{i}}{n_{D}},
$$

where $n_{D}$ stands for the number of teams that dismissed their coach and $n_{N d}$ stands for the number of teams that did not. This expression can be written as:

$$
\overline{A E M}_{N d}=-\frac{n_{D}}{n_{N d}} \times \overline{A E M}_{D}
$$

Consequently, for the two leagues and the two seasons, $\overline{A E M}_{N d}=-\frac{28}{52} \times 1.9638=-1.0574$.

\begin{tabular}{|c|c|c|c|c|c|c|c|}
\hline \multicolumn{4}{|c|}{ Ligue 1 2015-2016 } & \multicolumn{4}{|c|}{ English Premier League 2015-2016 } \\
\hline Club & Head Coach & Date of Dismissal & Game Day & Club & Head Coach & Date of Dismissal & Game Day \\
\hline Lille & Renard & 11 November 2015 & 13th & Liverpool & Rodgers & 4 October 2015 & 8th \\
\hline Troyes & Furlan & 3 December 2015 & 16th & Sunderland & Advocaat & 4 October 2015 & 8th \\
\hline Lyon & Fournier & 24 December 2015 & 19th & Aston Villa & Sherwood & 24 October 2015 & 10th \\
\hline Montpellier & Courbis & 24 December 2015 & 19th & Swansea City & Monk & 9 December 2015 & 15th \\
\hline Rennes & Montanier & 20 January 2016 & $21 \mathrm{st}$ & Chelsea & Mourinho & 9 December 2015 & 16th \\
\hline Montpellier & Baills & 26 January 2016 & 22nd & Newcastle United & McClaren & 11 March 2016 & 29th \\
\hline Bastia & Printant & 28 January 2016 & 22nd & Everton & Martinez & 12 May 2016 & 37 th \\
\hline Troyes & Robin & 4 February 2016 & 24th & & & & \\
\hline Toulouse & Arribagé & 27 February 2016 & 28th & & & & \\
\hline Bordeaux & Sagnol & 14 March 2016 & 30th & & & & \\
\hline Marseille & Michel & 19 April 2016 & 34th & & & & \\
\hline Reims & Guégan & 23 April 2016 & 34th & & & & \\
\hline \multicolumn{4}{|c|}{ Ligue 1 2016-2017 } & \multicolumn{4}{|c|}{ English Premier League 2016-2017 } \\
\hline Marseille & Passi & 20 October 2016 & 10th & Swansea City & Guidolin & 3 October 2016 & 7th \\
\hline Lorient & Ripoll & 23 October 2016 & 10th & Crystal Palace & Pardew & 22 December 2016 & 17th \\
\hline Lille & Antonetti & 22 November 2016 & 13th & Swansea City & Bradley & 27 December 2016 & 18th \\
\hline Nantes & Girard & 1 December 2016 & 16th & Hull City & Phelan & 3 January 2017 & 20th \\
\hline Montpellier & Hantz & 30 January 2017 & $23 \mathrm{rd}$ & Leicester City & Ranieri & 23 February 2017 & 25th \\
\hline Bastia & Ciccolini & 27 February 2017 & 27 th & Middlesbrough FC & Karanka & 16 March 2017 & 27th \\
\hline
\end{tabular}

Table 4. Head Coach dismissals over seasons 2015-2016 and 2016-2017 for the Ligue 1 and English Premier League.

Whatever the league and the season, the mean $A E M$ of teams that dismissed their coach is positive. Symmetrically, the mean of the teams that did not dismiss their coach is negative. As for Ligue 1, $\overline{A E M}_{N d}=-\frac{10}{10} \times 1.4453=-1.4453$ for the $2015-2016$ season and $\overline{A E M}_{N d}=-\frac{6}{14} \times 2.5756=-1.1038$ for the 2016-2017 season. As for the English Premier League, $\overline{A E M}_{N d}$ is equal to -1.5153 for the 2015-2016 season and -0.3587 for the 2016-2017 season and $\overline{A E M}_{D}$ is equal to 2.8142 for the 2015-2016 season and 1.0761 for the 2016-2017 season.

In addition, it is clear from Table 3 that most of the teams that dismissed their coach (in bold) underperformed $-61 \%$ of the teams that exhibit a positive average expected margin (22 teams out of 36) dismissed their coach. Only 13\% of the teams displaying a negative average expected margin dismissed their coach (6 teams out of 44). Figure 8 displays the distribution of teams according to their average expected margin (grey bars). The black bars show the distribution of teams that dismissed their head coach. For example, the number of teams having an $A E M_{i}$ between 0 and -1 is equal to 18 . Among those teams, 4 teams dismissed their coach. Among the 15 teams that exhibited an $A E M_{i}$ greater than 2, 14 teams dismissed their head coach (93\%). As for the teams displaying an $A E M_{i}$ 
greater than 1 ( 23 teams), 83\% of them dismissed their coach. The link between bad performance and the dismissal of coaches is clearly established here.

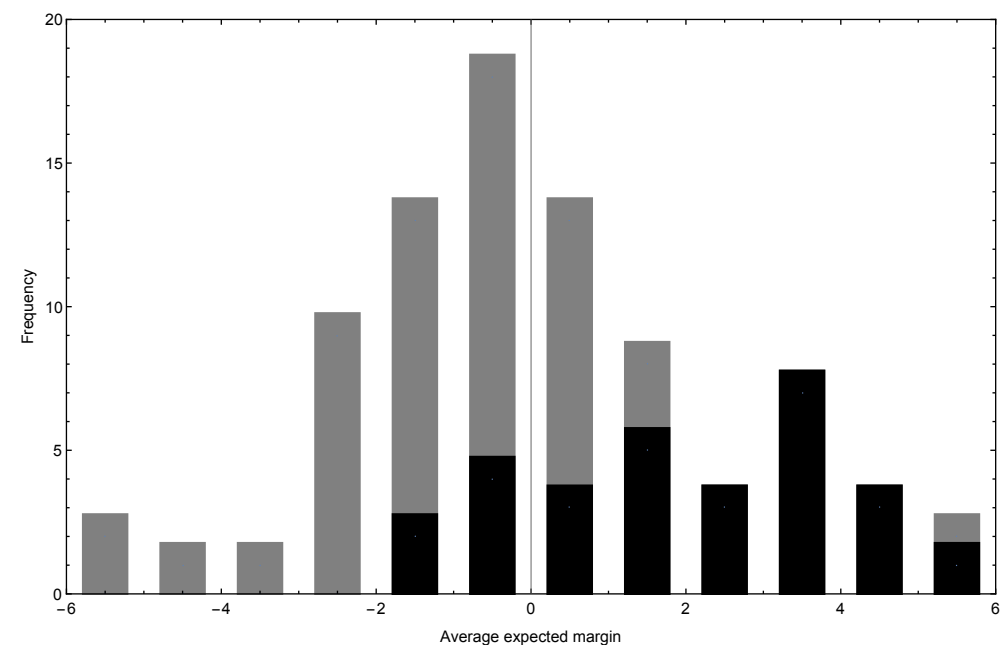

Figure 8. Dismissals and the distribution of average expected margins.

To show graphically the relation between performance and dismissal (Figure 9), we plot the expected final rank computed at the beginning of the season, $E R_{i}^{0}$, against the average expected final rank for teams that dismissed their coach (circles) and for those that did not (black dots). The figure displays 80 points (two leagues of 20 clubs for two seasons). The average expected margin, $A E M_{i}$ is measured by the distance of the points (circles or black dots) to the first bisector. The further above (below) the bisecting line the points are, the lower (higher) the performance of the teams. It is clear from the figure that most of the points above the first bisector are circles showing that most of the under-performing clubs dismissed their coach, whereas clubs that performed quite well on average did not dismiss their coach (the black dots are mostly below the first bisector).

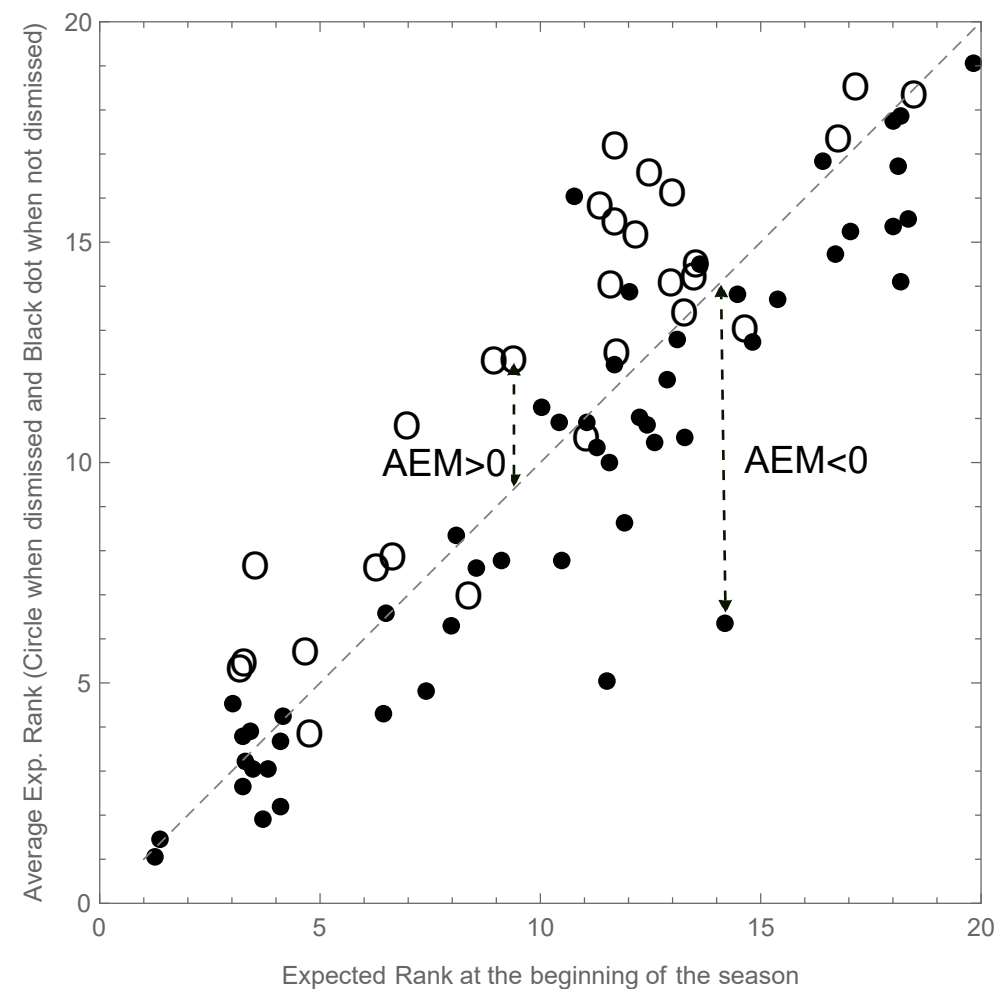

Figure 9. Expected rank and Coach dismissal. 
We see that a few well performing teams dismissed their head coach (a few circles are below the bisecting line). The reason might be because the national league championships are not the only competitions in which the teams play. There are also other competitions, such as the Coupe de France and the FA Cup in England, that may have an influence on the perceived performance of teams. Dismissals may occur because of poor performances in those competitions. For example, this was the case for the French club Stade Rennais (Rennes) whose coach, Philippe Montanier, was dismissed in 2016 even though the team performance in Ligue 1 was better than expected $\left(A E M_{\text {Rennes }}=-1.4731\right)$. Coach Montanier was dismissed under pressure from fans who blamed him for the elimination of the team from the Coupe de France against Bourg-en-Bresse, a poorly ranked team of the French Ligue $2 .^{5}$

The interpretation of our results is straightforward: Almost all the clubs whose average expected performance was below pre-season expectations dismissed their coach. Another question is whether the club decision to dismiss is different according to the seasons and the leagues. To investigate this question, we estimate the following equation on the sample of teams that dismissed their head coach:

$$
E M_{i}^{t}=\beta_{0}+\beta_{1} \text { season }_{t}+\beta_{2} \text { league }_{i}+\beta_{3} \text { season }_{t} \times \text { league }_{i},
$$

where

$$
\text { season }_{t}= \begin{cases}0 & \text { for season 2015-2016 } \\ 1 & \text { for season 2016-2017 }\end{cases}
$$

and

$$
\text { league }_{i}= \begin{cases}0 & \text { for clubs playing in the English Premier league } \\ 1 & \text { for clubs playing in the Ligue } 1 .\end{cases}
$$

The results are reported in Table 5. We have 1036 observations (28 dismissed coaches times 37 game days) Parameter $\beta_{0}$ is the mean average expected margin of English Premier League teams that dismissed their head coach over the 2015-2016 season $\left(\overline{A E M}_{D}\right)$. The mean average expected margin is significantly lower for the 2016-2017 season $\left(\beta_{1}=-1.73\right)$. This is mostly because Sunderland's head coach was not dismissed despite the poor performance of his team $\left(A E M_{\text {Sunderland }}=5.41\right)$. For the Ligue 1, the difference in the mean average expected margin between the 2015-2016 and 2016-2017 seasons is positive and significant $\left(\beta_{0}+\beta_{1}+\beta_{2}+\beta_{3}-\beta_{0}-\beta_{2}=\beta_{1}+\beta_{3}=-1.73+2.86=1.13\right)$.

Table 5. Estimation results (Pooled-OLS) ${ }^{\mathrm{a}}$.

\begin{tabular}{cc}
\hline Intercept & $2.8142^{* * *}$ \\
& $(18.2665)$ \\
season & $-1.7381^{* * *}$ \\
& $(-7.2821)$ \\
league & $-1.3689^{* * *}$ \\
& $(-6.8145)$ \\
season $\times$ league & $2.8683^{* * *}$ \\
& $(9.0131)$ \\
Adjusted $R^{2}$ & 0.0724 \\
Number of observations & 1036 \\
\cline { 2 - 2 }$t$-value in parentheses; ${ }^{* * *}$ indicate significance at $0.1 \%$
\end{tabular}

5 The question of assessing the overall performance of football teams by taking into account all the competitions has been raised by Picazo-Tadeo and González-Gómez (2010). 
The difference in the mean average expected margin between the Ligue 1 and the English Premier League is negative and significant for the 2015-2016 season $\left(\beta_{2}=-1.36\right)$ and positive and significant for the 2016-2017 season $\left(\beta_{0}+\beta_{1}+\beta_{2}+\beta_{3}-\beta_{0}-\beta_{1}=\beta_{2}+\beta_{3}=1.5\right)$. Even if the two leagues and the two seasons differ in terms of dismissal decisions, the common feature is that dismissal and poor performance are strongly related in both leagues for both seasons.

\section{The Effect of Dismissal on Team Performance}

In this section, we assess the impact of dismissal on team performance. Because of the perfect symmetry between the average expected margins of teams that dismissed their coach and the average expected margins of those that did not, we focus on the sub-sample of teams that dismissed their coach. To evaluate whether dismissal improves performance, we estimate the following equation:

$$
E M_{i}^{t}=\beta_{0}+\beta_{1} \text { dismiss }_{i t}+\epsilon_{i t}
$$

where

$$
\text { dismiss }_{i t}= \begin{cases}0 & \text { when } t \leq d, d \text { denotes the game day before the date of dismissal } \\ 1 & \text { when } t>d .\end{cases}
$$

The expected margin before dismissal is usually computed as: $E M_{i}^{t \leq d}=E R_{i}^{t}-E R_{i}^{0}$. The expected margin after dismissal takes the value of $E M_{i}^{t>d}=E R_{i}^{t}-E R_{i}^{d}$. It is as if a new season started for teams that dismissed their coach. The performance of the new coaches is assessed from date $d$ onward. For those coaches, the reference expected final rank is $E R_{i}^{d}$; it is not $E R_{i}^{0}$ anymore (see Figures $4-7$ for clubs that dismissed their coach). We also consider the same period of time in charge for coaches who were dismissed and those who took over. For example, if a team dismissed its coach at game day 10, we only consider the next 10 game days of coaching for the new coach. If a coach is dismissed at game day 25, we only take into account the last 13 game days of the former coach (the reference expected final rank is then computed at game day 12) and the 13 remaining game days of the season for the new coach (38-25). In that sample, the average coaching time period under consideration is about 12 game days. We thus focus on what we may consider as the short-term effects of coach dismissal.

In this equation, dismiss is a dummy variable that takes a value of 1 for the game days after dismissal and a value of 0 before. Parameter $\beta_{0}$ thus measures the mean average expected margin of teams before dismissal. If $\beta_{1}$ is negative and significant, it means that the mean average expected margin is significantly lower after the dismissal than before and consequently that the teams performed better after the dismissal than before. The results are given in Table 6 (1st column). Parameter $\beta_{1}$ is significant and equal to -0.455 , suggesting that the $\overline{A E M}$ after the dismissal is lower (by about $0.455)$ than the $\overline{A E M}$ before dismissal. The $\overline{A E M}$ is equal to 0.740 before dismissal and 0.285 after (0.740-0.455). According to that result, performance improved after dismissal, even if, on average, the teams of the new coaches still under-performed ( $\overline{A E M}$ is still positive after dismissal). We confirm here the results obtained by Scelles and Llorca (2020) that coach change improved the post-dismissal performance of the French Ligue 1 teams over the 2000-2016 period. Symmetrically, the performance of teams that did not dismiss their coaches decreased on average. ${ }^{6}$

Figure 10 illustrates this result. The horizontal axis gives the expected margin of teams before dismissal $\left(E M_{i}^{t \leq d}\right)$, while the expected margin after dismissal is shown on the vertical axis $\left(E M_{i}^{t>d}\right)$. Each point in the figure corresponds to the same day of coaching for the former coach and for the new one. For example, if a coach is dismissed just before game day 8 , there will be 8 points in the figure regarding that team. The coordinates of the 1st point correspond to the expected margin of the former coach at game day 1 and to that of the new coach at game day 9 , which is the first day that the

6 It is because of this symmetry that we cannot use a control group. If the treatment (here the coach dismissal) improves the performance of the treated group on average, it will automatically hinder that of the non-treated group on average. 
new coach is in charge. The 8th point displays the expected margin of the former coach on her last game day in charge and that of the new coach on her 8th game day in place (game day 16). The dashed line represents the first bisector. The figure shows that a higher number of points are below the first bisector, illustrating the fact that the mean average expected margin is lower after than before dismissal. We also see that this may not be true for teams that over-performed before dismissal $\left(E M_{i}^{t \leq d}<0\right)$. For those teams (left-hand side of the figure), it seems that the number of points above the bisector is higher. It is as if teams that performed well before dismissal displayed a lower performance after dismissing their coach.

Table 6. Estimation results (Pooled-OLS) ${ }^{\mathrm{a}}$.

\begin{tabular}{ccc}
\hline & Specification 1 & Specification 2 \\
\hline Intercept & $0.740662^{* * *}$ & $1.23416^{* * *}$ \\
dismiss & $(6.39946)$ & $(9.18993)$ \\
& $-0.455647^{* * *}$ & $-1.12881^{* * *}$ \\
Perf & $(-2.78379)$ & $(-5.94359)$ \\
& & $-1.5963^{* * *}$ \\
dismiss $\times$ Perf & & $(-6.60906)$ \\
Adjusted $R^{2}$ & 0.0105502 & $2.17749^{* * *}$ \\
Number of observations & 634 & 0.079676 \\
\hline
\end{tabular}

${ }^{a} t$-value in parentheses; ${ }^{* * *}$ indicate significance at $0.1 \%$.

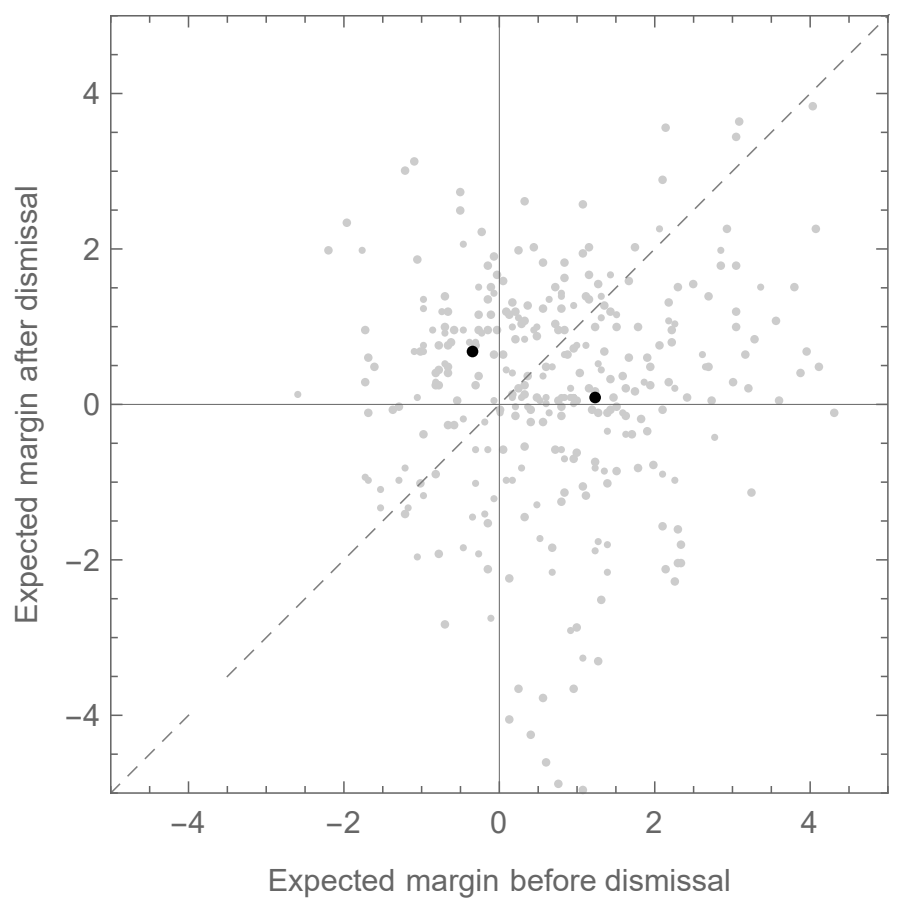

Figure 10. Expected margin before and after dismissal.

To investigate this issue econometrically, we estimate the following equation:

$$
E M_{i}^{t}=\beta_{0}+\beta_{1} \text { dismiss }_{i t}+\beta_{2} \operatorname{Perf}_{i}+\beta_{3} \text { dismiss }_{i t} \times \operatorname{Perf}_{i}+\epsilon_{i t}
$$

where

$$
\text { dismiss }_{i t}= \begin{cases}0 & \text { when } t \leq d, \text { where } d \text { denotes the game day before the date of dismissal } \\ 1 & \text { when } t>d .\end{cases}
$$


and

$$
\operatorname{Perf}_{i}=\left\{\begin{array}{cc}
0 & \text { for teams having a positive Average expected margin before } d \\
1 & \text { for teams having a negative Average expected margin before } d
\end{array}\right.
$$

The dummy variable Perf is equal to 0 for teams that under-performed before dismissal $\left(A E M_{i}^{t \leq d}>0\right)$ and 1 for those that over-performed before dismissal $\left(A E M_{i}^{t \leq d}<0\right)$. The results are reported in Table 6 (2nd column). All the estimated coefficients are significantly different from zero. The mean average expected margin of under-performing teams is equal to 1.23 before dismissal $\left(\beta_{0}\right)$ and 0.10 after $\left(\beta_{0}+\beta_{1}\right)$. On the other hand, the mean average expected margin of over-performing teams is equal to -0.36 before dismissal $\left(\beta_{0}+\beta_{2}\right)$ and 0.68 after $\left(\beta_{0}+\beta_{1}+\beta_{2}+\beta_{3}\right)$. The two points $(1.23,0.10)$ and $(-0.36,0.68)$ are displayed in Figure 10 (black dots). Regarding the teams that over-performed before they dismissed their coach, that point is above the first bisector; for those teams that did not perform well before dismissal, the point is below the bisecting line. This result suggests that for teams performing quite well before dismissing their coach, dismissal hinders performance. Conversely, for teams performing poorly before dismissal, dismissing their coach enhances performance. Poulsen (2000) finds similar results regarding the top two English divisions for the 1993-1994 to 1997-1998 seasons. According to him, "if teams are doing well, or just "not to bad" then there appears to be no gain from sacking the manager". We may use a medical allegory to illustrate our results: Dismissing a coach is like taking medication, it may help if you are sick but if you take medication for an illness you do not have, you will only experience the negative side effects.

We may wonder whether this result is not due to a regression to the mean phenomenon. It might be the case that poor team performance is due to bad luck. But bad luck is unlikely to last for long. After a while, performance will improve whether the coach is changed or not. The improvement in performance would thus be a pure statistical phenomenon. The same statistical effect may be observed for teams performing well before dismissal and whose performance is hindered after dismissing their coach. However, luck is probably not the right explanation here because the period of time we consider is quite long: 12 game days on average. A team may be unlucky for a few game days, but if it is unlucky for 12 game days in a row, the cause may not be only a matter of bad luck.

\section{Conclusions}

In this paper, we propose an innovative method for assessing the performance of professional sport teams using Monte Carlo simulation. To apply the method, we need only information regarding the teams' stock of talent. We use the team wage costs as a proxy for that stock. The key principle of our method is to compare the average expected performance, expressed as the average expected final position over the season, with the position expected before the season starts (depending only on the teams' relative payroll). We call that difference an average expected margin.

We show that in-season head coach dismissals are the result of poor performance over the season in comparison to pre-season expectations. Among the teams displaying an average expected margin greater than two, that is, an average expected final ranking two positions lower than what was expected at the beginning of the season, $93 \%$ of them dismissed their coach. For the Ligue 1, the average expected margin computed at the game day just before dismissal is equal to 3.32 for the 2015-2016 season and 3.50 for the 2016-2017 season. It means that on average the expected final ranking at date of dismissal is between 3 and 4 positions lower than the pre-season expectations. For the English Premier League, it is equal to 3.19 and 2.11 for the 2015-2016 and 2016-2017 season, respectively. We also find that dismissing a coach may enhance performance only if the team under-performed before the dismissal. According to our findings, even if a team improves its results after coach dismissal, it may still perform below expectations. Conversely, if the teams performed well before the coach was dismissed, the dismissal hinders performance.

There is no obstacle to using the same method for professional teams in other sports. The method is easily reproducible and does not require much information in order to be applied. 
Author Contributions: Y.R.: conceptualization, methodology, validation, resources, data curation, project administration, writing; M.P.: conceptualization, methodology, writing. Both authors have read and agreed to the published version of the manuscript.

Funding: This research received no external funding.

Acknowledgments: The authors are grateful to the participants in the 36th Journées de Microéconomie appliquée, Casablanca, Morocco (June 2019) for fruitful exchanges. They also thank the two anonymous reviewers of this journal whose comments have contributed to improving the quality of the paper.

Conflicts of Interest: The authors declare no conflict of interest.

\section{References}

Allen, W. David, and Clint Chadwick. 2012. Performance expectations, and managerial dismissal: Evidence from the national football league. Journal of Sports Economics 13: 337-63. [CrossRef]

Ashton, John K., Bill Gerrard, and Robert Hudson. 2011. Do national soccer results really impact on the stock market? Applied Economics 43: 3709-17. [CrossRef]

Audas, Rick, John Goddard, and W. Glenn Rowe. 2006. Modelling employment durations of NHL head coaches: Turnover and post-succession performance. Managerial and Decision Economics 27: 293-306. [CrossRef]

Barros, Carlos Pestana, Bernd Frick, and José Passos. 2009. Coaching for survival: The hazards of head coach careers in the german "bundesliga". Applied Economics 41: 3303-11. [CrossRef]

Breunig, Robert, Bronwyn Garrett-Rumba, Mathieu Jardin, and Yvon Rocaboy. 2014. Wage dispersion and team performance: A theoretical model and evidence from baseball. Applied Economics 46: 271-81. [CrossRef]

d'Addona, Stefano, and Axel Kind. 2014. Forced manager turnover in english soccer leagues: A long-term perspective. Journal of Sports Economics 15: 150-79. [CrossRef]

de Dios Tena, Juan D., and David Forrest. 2007. Within-season dismissal of football coaches: Statistical analysis of causes and consequences. European Journal of Operational Research 181: 362-73. [CrossRef]

Detotto, Claudio, Dimitri Paolini, and J. D. Tena. 2018. Do managerial skills matter? an analysis of the impact of managerial features on performance for Italian football. Journal of the Operational Research Society 69: 270-82. [CrossRef]

Flores, Ramón, David Forrest, and J. D. Tena. 2012. Decision taking under pressure: Evidence on football manager dismissals in Argentina and their consequences. European Journal of Operational Research 222: 653-62. [CrossRef]

Frick, Bernd, Carlos Barros, and Joachim Prinz. 2010. Analysing head coach dismissals in the german "bundesliga" with a mixed logit approach. European Journal of Operational Research 200: 151-59. [CrossRef]

Hill, Gregory C. 2009. The effect of frequent managerial turnover on organizational performance: A study of professional baseball managers. The Social Science Journal 46: 557-70. [CrossRef]

Holmes, Paul. 2011. Win or go home: Why college football coaches get fired. Journal of Sports Economics 12: 157-78. [CrossRef]

Hughes, Mathew, Paul Hughes, Kamel Mellahi, and Cherif Guermat. 2010. Short-term versus long-term impact of managers: Evidence from the football industry. British Journal of Management 21: 571-89. [CrossRef]

Kahn, Lawrence. 2006. Race, performance, pay, and retention among national basketball association head coaches. Journal of Sports Economics 7: 119-49. [CrossRef]

Koning, Ruud H. 2003. An econometric evaluation of the effect of firing a coach on team performance. Applied Economics 35: 555-64. [CrossRef]

Lago-Peñas, Carlos. 2011. Coach mid-season replacement and team performance in professional soccer. Journal of Human Kinetics 28: 115-22. [CrossRef] [PubMed]

Mixon, Franklin G., and Len J. Trevino. 2004. How race affects dismissals of college football coaches. Journal of Labor Research 25: 645-56. [CrossRef]

Picazo-Tadeo, Andréz J., and Francisco González-Gómez. 2010. Does playing several competitions influence a team's league performance? Evidence from Spanish professional football. Central European Journal of Operations Research 18: 413-432. [CrossRef]

Pieper, Jan, Stephan Nüesch, and Egon Franck. 2014. How performance expectations affect managerial replacement decisions. Schmalenbach Business Review 66: 5-23. [CrossRef] 
Poulsen, Rolf. 2000. Should he stay of should he go? estimating the effect of firing the manager in soccer. Chance 13: 29-32. [CrossRef]

Salgado-Barandela, Jesyca, Angel Barajas, A., and Patricio Sánchez-Fernández. 2017. Economic impact of sport: Topic of growing interest for the scientific literature. Revista Internacional de Medicina y Ciencias de la Actividad Física y del Deporte 17: 729-55.

Salomo, Soren, and Kai Teichmann. 2000. The relationship of performance and managerial succession in the german premier football league. European Journal of Sport Management 7: 99-119.

Scelles, Nicolas and Matthieu Llorca. 2020. Head coach change and team performance in the French men's football Ligue 1, 2000-2016. Economics Bulletin 40: 920-37.

van Ours, Jan C., and Martin A. van Tuijl. 2016. In-season head-coach dismissals and the performance of professional football teams. Economic Inquiry 54: 591-604. [CrossRef]

White, Philip, Sheldon Persad, and Chris J. Gee. 2007. The effect of mid-season coach turnover on team performance: The case of the national hockey league (1989-2003). International Journal of Sports Science and Coaching 2: 143-52. [CrossRef]

(C) 2020 by the authors. Licensee MDPI, Basel, Switzerland. This article is an open access article distributed under the terms and conditions of the Creative Commons Attribution (CC BY) license (http://creativecommons.org/licenses/by/4.0/). 